Gut, 1981, 22, 187-189

\title{
Impaired immunity in patients with inflammatory bowel disease and hyposplenism: the response to intravenous $\varphi$ X174
}

\author{
F P RYAN, J VERRIER JONES, J K WRIGHT, AND C D HOLDSWORTH \\ From the Northern General and Royal Hallamshire Hospitals, Sheffield, and \\ Southmeads Hospital, Bristol
}

SUMMARY Eight patients with inflammatory bowel disease were tested for their ability to mount a serological response to the intravenous particulate antigen $\phi X 174$. Seven patients had extensive ulcerative colitis and one patient extensive Crohn's colitis, four having severe hyposplenism and four normal splenic function. The antibody response to $\varphi$ X174 was grossly impaired in those with hyposplenism.

We have previously reported the occurrence of hyposplenism in 13 out of 36 patients with ulcerative colitis and our more recent unpublished observations have shown that hyposplenism is almost as common in Crohn's disease. The clinical importance of this has still to be fully assessed, but, of the eight patients with ulcerative colitis and hyposplenism who proceeded to colectomy, one suffered pneumococcal septicaemia and three others had clinical evidence of Gram-negative endotoxaemia in the immediate post-colectomy period. ${ }^{1}$ It therefore seemed important to determine if the hyposplenism associated with inflammatory bowel disease resulted in an impaired immune response which could predispose to postoperative complications. The serological response to $\varphi \mathrm{X} 174$ was chosen because it tests the patient's ability to mount an immunological response to a living intravenous particulate antigen.

\section{Methods}

Seven patients with ulcerative colitis and one patient with Crohn's disease were tested. All eight patients had extensive colonic disease. Three of the seven with ulcerative colitis and the one patient with Crohn's disease had severe hyposplenism on the basis of impaired clearance of ${ }^{51} \mathrm{Cr}$-labelled heatdamaged red cells together with vestigial spleens demonstrated by isotope scanning or at surgery. The four remaining patients with ulcerative colitis had normal splenic function (Table). Two of the

Received for publication 30 October 1980 patients had had pan-proctocolectomy one year and six months before serological testing, and in these, as hyposplenism usually improves after colectomy, it was confirmed that hyposplenism was still severe at the time of testing. The remaining six patients were either receiving no specific therapy or only sulphasalazine, patients taking steroids in any form being excluded. The criteria for diagnosis of inflammatory bowel disease included sigmoidoscopic appearance, barium studies, rectal biopsy histology, and in three cases histology of the resected colons.

The method of preparing sterile, pyrogen-free bacteriophage suitable for intravenous injection has been described previously. ${ }^{2}$ Only batches of phage shown to be both sterile and pyrogen-free were used. Each patient was injected intravenously with $1 \mathrm{ml}$ containing $2 \times 10^{9}$ plaque forming units of phage and blood sampling carried out before injection and at intervals for 28 days after injection (the primary phase). After an additional period of two weeks, a second identical injection of phage was made and samples of blood taken as before (the secondary phase). The blood samples were allowed to clot at room temperature and the serum removed for storage at $-20^{\circ} \mathrm{C}$.

Antibody activity in the samples after primary and secondary immunisation was assessed by measuring the inactivation of a standard concentration of bacteriophage by serial doubling dilutions of serum, the dilution of serum which neutralised $50 \%$ of the standard being expressed as the $\mathrm{SD}_{50}{ }^{2}$ In two of the patients with hyposplenism and two of those with normal spleens the serum with the peak titre of 
Table Splenic size and function in eight patients studied

\begin{tabular}{|c|c|c|c|}
\hline Patient & Diagnosis & $\begin{array}{l}\text { Spleen size } \\
\text { (scan area) } \\
\text { (normal } \\
64 \cdot 6 \pm 15 \cdot 6 \text { ) }\end{array}$ & $\begin{array}{l}\text { Splenic } \\
\text { function } \\
\left(T_{1 / 2}, \text { min }\right) *\end{array}$ \\
\hline \multicolumn{4}{|l|}{ Normal } \\
\hline PC & Ulcerative colitis & $65.4 \mathrm{~cm}^{2}$ & $12 \cdot 9$ \\
\hline FC & Ulcerative colitis & $42 \cdot 5 \mathrm{~cm}^{2}$ & $7 \cdot 5$ \\
\hline JL & Ulcerative colitis & $64 \cdot 2 \mathrm{~cm}^{2}$ & $11 \cdot 2$ \\
\hline JB & Ulcerative colitis & Not assessed & $13 \cdot 8$ \\
\hline \multicolumn{4}{|l|}{ Hyposplenic } \\
\hline JE & Ulcerative colitis & $\begin{array}{l}2 \times 5 \mathrm{~cm} \ddagger \\
\text { (operative) }\end{array}$ & $130.4 \uparrow$ \\
\hline LM & Ulcerative colitis & $-\ddagger$ & $92 \cdot 5 \dagger$ \\
\hline EB & Crohn's disease & $\begin{array}{l}\text { Vestigialł } \\
\text { (operative) }\end{array}$ & $79 \cdot 8 \dagger$ \\
\hline GB & Ulcerative colitis & $\begin{array}{l}6 \times 5 \mathrm{~cm} \ddagger \\
\text { (operative) }\end{array}$ & $55+$ \\
\hline
\end{tabular}

*Splenic function $\mathrm{T}_{1 / 2}$ refers to the time taken to clear $50 \%$ of the intravenously injected isotopically labelled autologous red cells from the circulation.

+ Hyposplenism is indicated by a time greater than 17.5 minutes. $\ddagger$ Denotes no uptake over splenic area on scanning. Splenic size assumed to be vestigial and confirmed in three cases at operation.

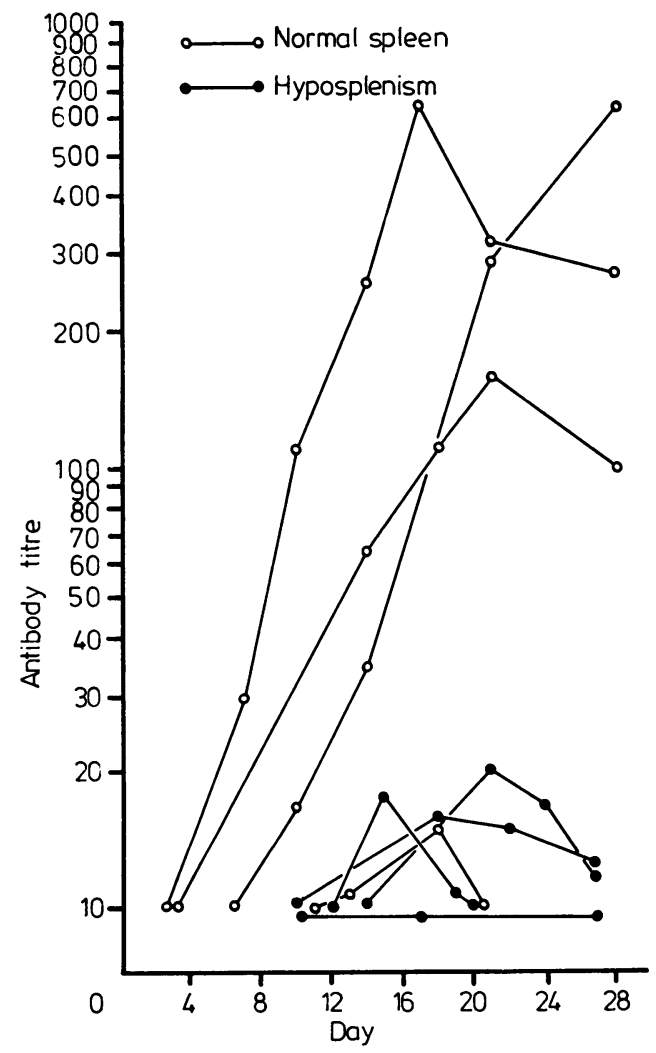

Fig. 1 Antibody responses after primary immunisation with $\varphi$ XI74. secondary response was fractionated on a Sephadex G200 column to separate the IgM and IgG antibodies, the fractions containing IgM and IgG being characterised by immunoelectrophoresis against an antiserum to whole human serum. The relative proportions of the peak response in each antibody class could then be calculated by estimating the $\mathrm{SD}_{50}$ of the fractions as above.

\section{Results}

\section{PRIMARY RESPONSES}

All four patients with hyposplenism had abnormally low primary responses with peak titres of antibody of less than 20. Three of the four patients with normal splenic function had normal responses (Fig. 1) with peak titres of 160,640 , and 640.

\section{SECONDARY RESPONSES}

These were markedly impaired in all four patients with hyposplenism, with peak titres of $0,80,160$, and 640 . In the four patients with normal splenic function the responses were normal (Fig. 2), with titres of 10,000 or more.

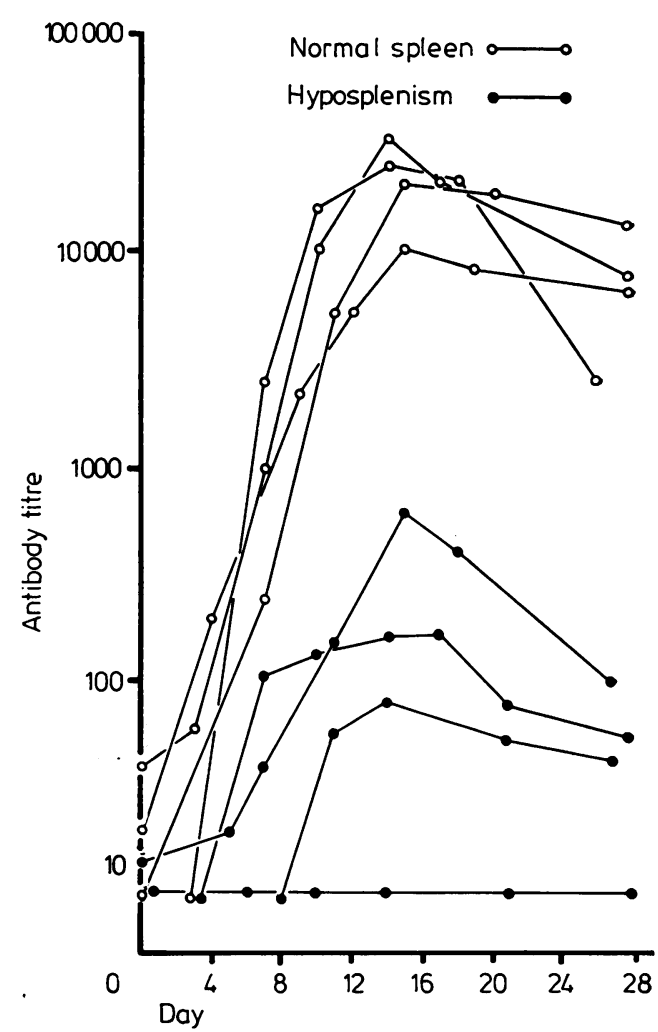

Fig. 2 Antibody responses after secondary immunisation with $\varphi X 174$. 
IMMUNOGLOBULIN CLASS OF ANTIBODY In the only two patients with hyposplenism who were tested (LM and GB), the only appreciable activity was found in the IgM fraction, implying that there was not only a quantitative deficiency of serological response but also a failure to switch from the normal IgM primary response to IgG secondary response. Rather surprisingly, in the two patients with normal splenic function the secondary response was again mainly IgM mediated with less than $20 \%$ of the total antibody in the IgG fraction.

\section{Discussion}

A marked impairment of response to the intravenous particulate antigen, $\varphi \times 174$, has been demonstrated in the four patients with hyposplenism when compared with the normal antibody titres developed in four patients with similarly extensive ulcerative colitis but with normal splenic function. These findings are similar to the results found in coeliac disease by Baker et al. ${ }^{3}$ when impairment of the secondary response to intravenous $\varphi$ X174 was also found to be particularly associated with small splenic size on isotopic scanning. The impairment reported in our four patients with hyposplenism is rather more marked than that shown in the previous patients studied with coeliac disease, but this is presumably explained by the fact that our subjects were chosen for their severe hyposplenism, whereas the coeliac patients were less selected and would be likely to have lesser degrees of hyposplenism.

The failure of all four patients whose peak titre sera were fractionated to convert to an IgG mediated secondary response is again similar to that reported in patients with coeliac disease. Although the numbers tested were small and the results need further corroboration, both the low titre serological response and the failure to convert to a secondary IgG mediated response in ulcerative colitis appear to be contrary to the normal response to intravenous $\varphi$ X174 reported in patients suffering from Crohn's disease. ${ }^{4}$ These authors reported no qualitative or quantitative abnormality in antibody response, but the splenic function of their patients was not known.

It is impossible to say if the abnormality in response to intravenous particulate antigen results from loss of the spleen or from a more widespread disturbance of lymphoreticular function which it is claimed is associated with hyposplenism in coeliac disease. ${ }^{5}$ In the two patients with normal splenic function, the failure of conversion to an IgGmediated response after secondary immunisation could imply a lesser defect in reticuloendothelial function not demonstrated by the heat-damaged red cell clearance test.

In animals the most clearly established role of the spleen in immunity is as the source of antibody to particulate intravenous antigen. ${ }^{6}$ In the light of this our findings are not unexpected. Their clinical relevance is uncertain, but the impaired immunity may have contributed to the pneumococcal septicaemia observed postoperatively in one of our hyposplenic patients. ${ }^{1}$ Impaired immunity or reticuloendothelial functions is also likely to account for the syndrome of endotoxic shock with disseminated intravascular coagulation which we have observed postoperatively on several occasions in our hyposplenic patients immediately after panproctocolectomy. ${ }^{1}$

We would like to thank Professor M G McEntegart and Mr B M Jones in the Department of Medical Microbiology, Sheffield University Medical School, and Dr P Hughes of the Department of Medicine at the Northern General Hospital, Sheffield, for their advice and help in this study.

\section{References}

${ }^{1}$ Ryan FP, Smart RC, Holdsworth CD, Preston FE. Hyposplenism in inflammatory bowel disease. Gut 1978; 19: $50-5$.

${ }^{2}$ Peacock DB, Jones JV, Gough M. The immune response to $\varphi$ X174 in man. I. Primary and secondary antibody production in normal adults. Clin Exp Immunol 1973; 13: 497-513.

${ }^{3}$ Baker PG, Jones JV, Peacock DB, Read AE. The immune response to $\varphi \mathrm{X} 174$ in man. III. Evidence for an association between hyposplenism and immunodeficiency in patients with coeliac disease. Gut 1975; 16: 538-42.

${ }^{4}$ Bucknall RC, Jones JV, Peacock DB. The immune response to $\varphi$ X174 in man. Primary and secondary antibody production in patients with Crohn's disease. Digest Dis 1975; 20: 430-6.

${ }^{5}$ McCarthy CF, Fraser ID, Evans KT, Read AE. Lymphoreticular dysfunction in idiopathic steatorrhoea. Gut 1966; 7: 140-8.

${ }^{6}$ Ellis EF, Smith RT. The role of the spleen in immunity. Pediatrics 1966; 37: 111-9. 